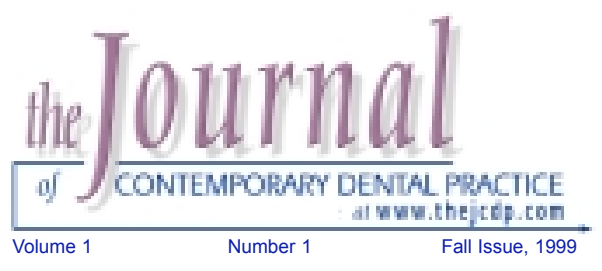

\title{
The Concept of "Risk" and the Emerging Discipline of Periodontal Medicine
}

\section{David W. Paquette, DMD, MPH, DMSc}

Phoebus Madianos, DMD, PhD; Steven Offenbacher, DDS, PhD; James D. Beck, PhD; Ray C. Williams, DMD Department of Periodontology, School of Dentistry

University of North Carolina, Chapel Hill, NC

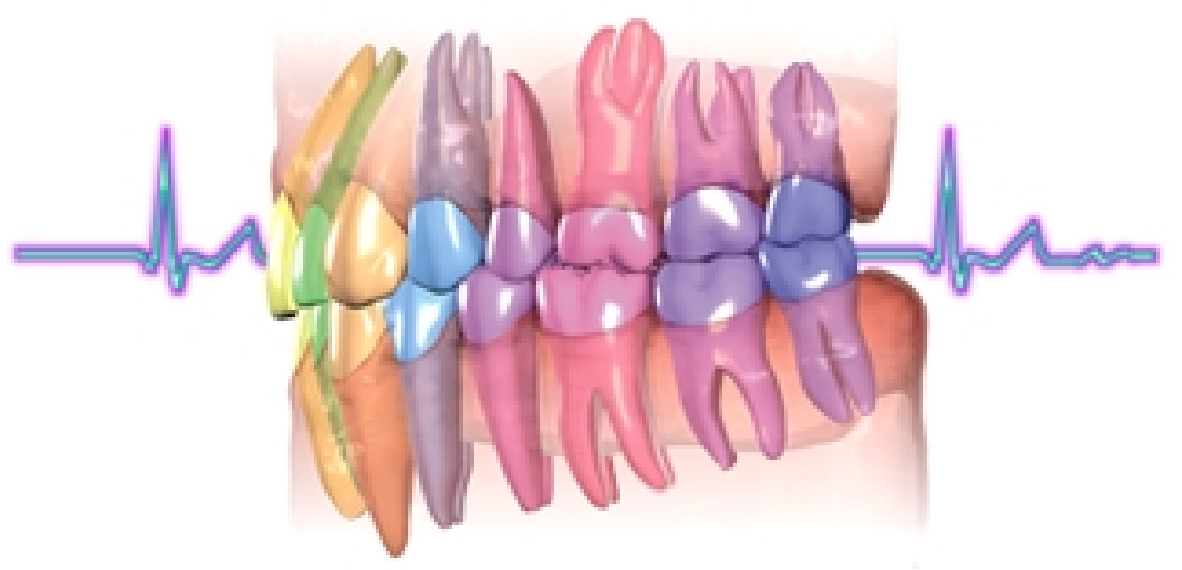

Abstract

Dental clinicians intuitively weigh patient risks for developing disease and use that information for making treatment decisions and recommendations. Periodontitis, for instance, is one oral disease with documented risk factors including smoking, specific plaque bacteria and diabetes mellitus. While this link between systemic disease and periodontitis was thought to be unidirectional, mounting evidence in the last decade suggests that the relationship may be bi-directional. Cross sectional and case control studies indicate that periodontitis may confer two and seven-fold elevations in risk for cardiovascular disease and premature low birth weight respectively. While these early studies indicate potential associations between oral and systemic health, they support the central hypothesis that periodontitis triggers both local and systemic host inflammatory responses. Consequently, a new discipline, periodontal medicine, has emerged in dentistry which seeks to further define these interrelationships through scientific inquiry. Ultimately, this new knowledge may prove useful in intervention strategies to reduce patient risks and prevent systemic disease outcomes. This manuscript clarifies the concept of risk, traces the emergence of periodontal medicine and serves as a resource for the oral health professional in assessing and utilizing the current evidence on periodontal-systemic disease connections.

Key Words: Risk, risk factors, risk assessment, periodontal diseases, pathophysiology, periodontitis, cardiovascular diseases, infant, low birth weight 


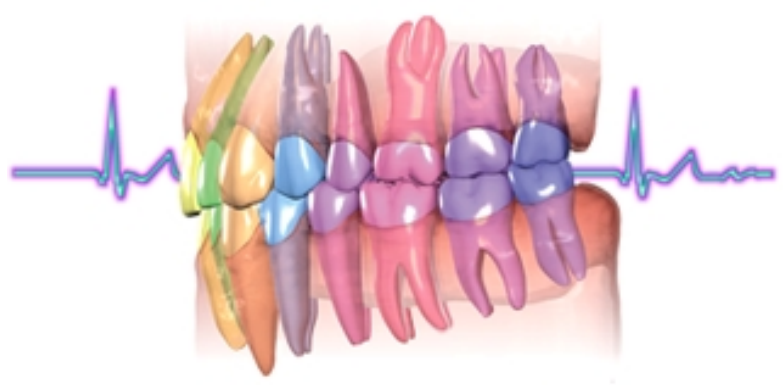

\section{Introduction}

As clinicians, we deal with the concept of risk on a day-to-day basis in terms of our assessment of oral diseases, outcomes and therapies. Critical clinical decisions are made based on our interpretation of these risks. When we turn to our evidence base for guidance on these decisions, we often encounter a cacophony of confusing messages. One random citation supports an exposure, behavior or genetic profile as conferring risk for a disease process, while another may refute it. Indeed, the growing number of biomedical cita- tions on risk may further amplify our confusion. Searches in MEDLINE databases reveal a steady increase in the proportion of articles with risk in the title or abstract, from $0.1 \%$ in 1967 to $5 \%$ in $1991 .{ }^{1}$ This trend is true not only for general medicine journals (e.g., Journal of the American Medical Association, The New England Journal of Medicine), but also for specialty journals (e.g., Anesthesiology, Obstetrics and Gynecology). The largest increase in such citations has occurred in those journals devoted to epidemiology (e.g., American Journal of Epidemiology) where more than $50 \%$ of citations have lately concerned the concept of risk. Skolbekken credits this publication expansion to developments in probability statistics and to practice shifts towards risk management and health promotion. ${ }^{1}$ Over this same time interval, dentistry has witnessed similar incremental increases in citations dealing with risk especially as related to periodontal disease (Figure 1).

\section{Figure l. Incidence of medical/dental citations with risk and periodontal diseases listed as keysubject words (MEDLINE search).}

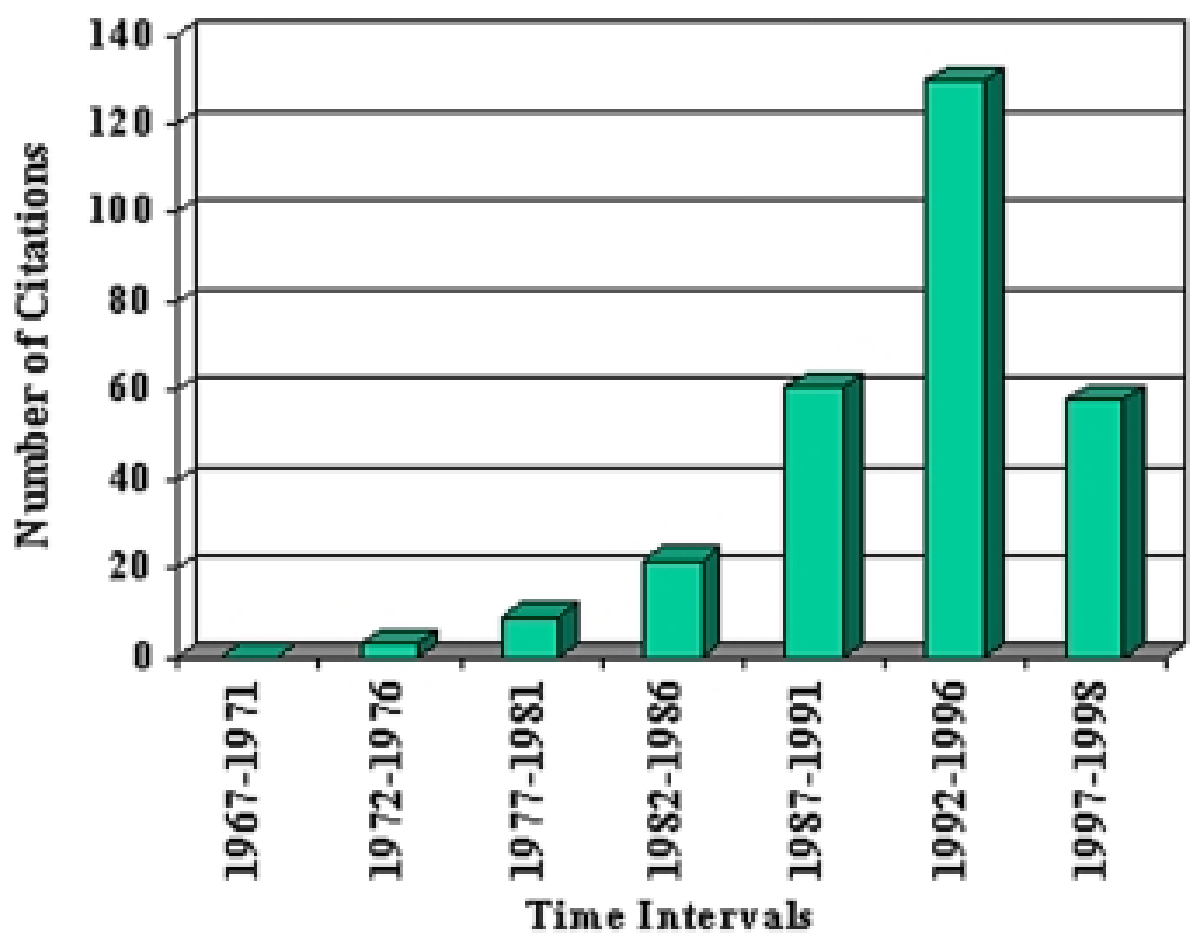

2

The Journal of Contemporary Dental Practice, Volume 1, No. 1, Fall Issue, 1999 
Indeed, a number of seminal studies published over the last decade have provided evidence suggesting that periodontal disease may confer risk for systemic conditions like cardiovascular disease and preterm low birth weight. ${ }^{2-5}$ From this evidence, a new dental discipline called "periodontal medicine" has emerged that seeks to define these relationships and potentially implement this knowledge in patient intervention strategies. This manuscript aims to (1) clarify the concept of risk, (2) trace the emergence of periodontal medicine, and (3) serve as a resource for the oral health professional in assessing and utilizing the current evidence on periodontal-systemic disease connections.

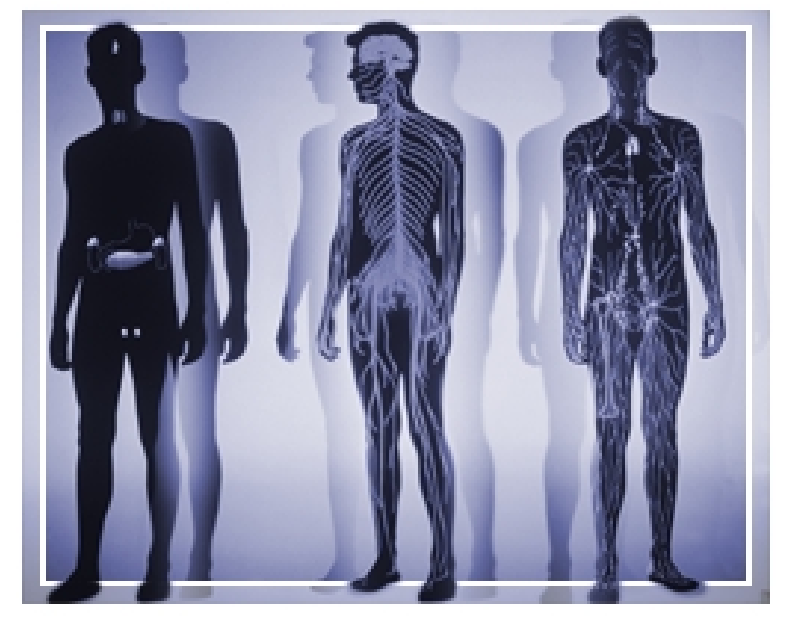

Risk and the Natural History of Diseases Risk is defined as the probability of developing a disease or experiencing a health status change given a defined condition. ${ }^{6,7}$ Numerically, risk is expressed as a dimensionless value between zero and one, and requires a time referent. Those attributes (genetic, environmental or behavioral) of the individual that increase the probability of the disease outcome are called "risk factors." Five lines of human evidence may support the cause-effect relationship conferred by risk factors (Table 1). ${ }^{8}$ There must be consistency or agreement among studies regarding the association between the purported risk factor and the disease outcome. Secondly, the association should be strong (i.e., the magnitude of the risk should be high with minimal error) and specific (i.e., independent of other known risk factors). The relationship should follow a time sequence such that the risk factor precedes the disease outcome that is measured. Increasing exposures of the factor in question also should lead to increased disease outcomes (dose-effect response). Lastly, the association should be biologically plausible given current data from other sources including animal models and in vitro assays.

The lines of evidence on risk detailed above may be derived from several human study designs that rank differently according to quality and weight (Table 1). Anecdotes, case histories and case

Table 1. Lines of evidence, rating and human study designs for documenting risk associations

\begin{tabular}{|c|c|c|}
\hline Lines of Evidence & $\begin{array}{c}\text { Quality and } \\
\text { weight Rating }\end{array}$ & Human Study Designs \\
\hline Consistency of agreement & \multirow{2}{*}{ High } & \multirow{8}{*}{$\begin{array}{l}\text { Randomized controlled (intervention) trials } \\
\text { Prospective longitudinal cohort studies } \\
\text { Retrospective cohort studies } \\
\text { Case control studies } \\
\text { Cross sectional studies } \\
\text { Case series } \\
\text { Case Histories } \\
\text { Anecdotes and clinical observations }\end{array}$} \\
\hline Strength of association & & \\
\hline Specificity of association & \multirow{2}{*}{ Moderate } & \\
\hline Appropriate time sequence & & \\
\hline Dose-effect response & \multirow{4}{*}{ Low } & \\
\hline Biological plausibility & & \\
\hline & & \\
\hline & & \\
\hline
\end{tabular}


series are designs with the lowest quality and weight; however, they may provide the basis for generating hypotheses. Case control studies select subjects with and without the disease outcome and compare the proportion of individuals with the risk factor or exposure in question. For case control studies, the data are often presented in a two-by-two or contingency table, and an odds ratio (OR) is calculated to express the rate of developing the disease given the presence of the risk factor relative to its absence (Table 2). In contrast, a cohort or longitudinal study selects subjects with and without the risk factor and monitors them prospectively or retrospectively for the disease outcome. This design ranks higher than the case control since it traces the correct time sequence and minimizes recall bias in subjects. Secondly, cohort studies most often quantitate a relative risk (RR) statistic that, like the odds ratio, relates the likelihood of having disease given the risk factor (Table 2). The highest ranked study design, the intervention or randomized clinical trial, prospectively evaluates whether alteration of the risk factor through patient or clinician actions (treatment) can prevent the disease onset or outcome.

Table 2. Presentation of data on risk of exposures and disease in a two-by-two contingency table for Case Control and Cohort Studies

\begin{tabular}{|c|c|c|c|c|}
\hline \multirow{2}{*}{} & & \multicolumn{2}{c|}{ Condition: } & \multirow{2}{*}{ Total } \\
\cline { 2 - 5 } & Yes & Yes & No & \\
\hline \multirow{2}{*}{ Exposure: } & No & A & B & A+B \\
\cline { 2 - 5 } & Total & C & D & C+D \\
\hline \multirow{2}{*}{ Total } & A+C & B+D & A+B+C+D \\
\hline
\end{tabular}

Rows represent two levels of exposure to the tested risk factor (exposed and nonexposed). Columns represent two levels of disease status (diseased and nondiseased). The following subject categories may be entered and totaled:

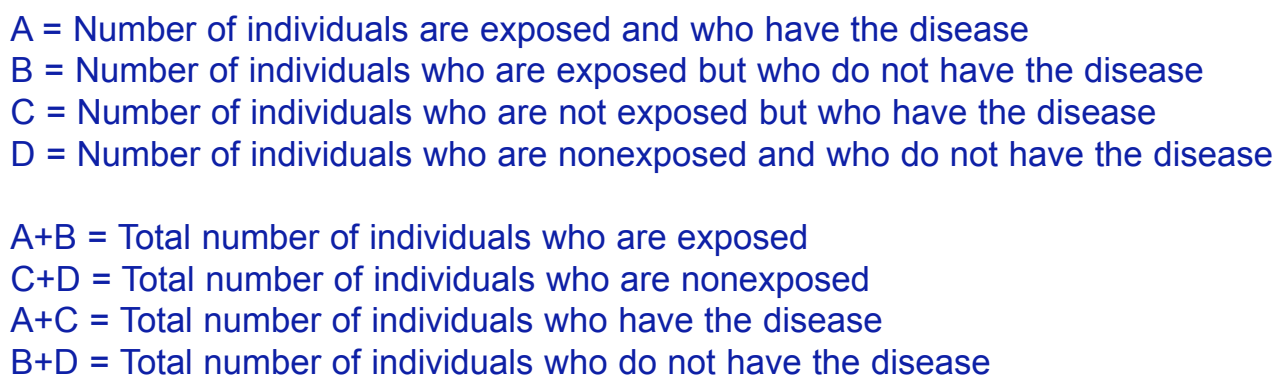


Table 2a. Presentation of data on risk of exposures and disease in a two-by-two contingency table for Case Control and Cohort Studies

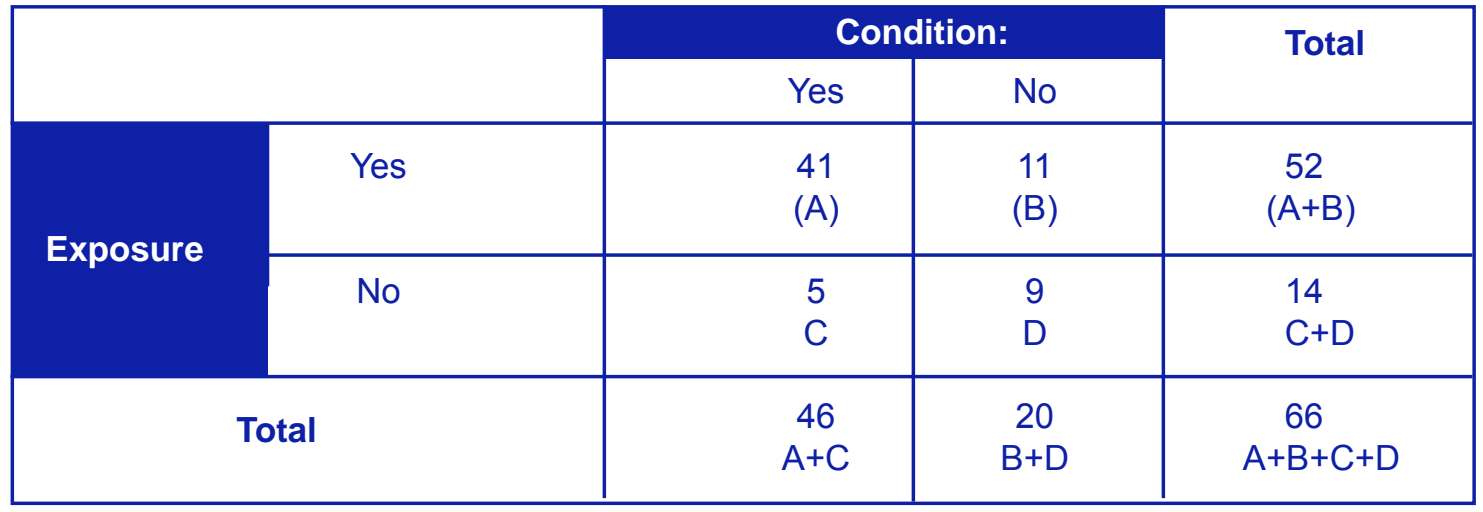

Data from a case control study of periodontal disease and preterm low birth weight delivery conducted by Offenbacher et al. (5). The unadjusted or raw odds ratio (OR) is calculated as the ratio of odds of exposure among cases to that among controls as follows:

$$
\text { OR }=\frac{A / C}{B / D}=\frac{A D}{B C}=\frac{(41)(9)}{(11)(5)}=6.71
$$

Conclusion: Female subjects with periodontal disease were 6.71 times more likely to have a low birth weight infant.

Table 2b. Presentation of data on risk of exposures and disease in a two-by-two contingency table for Case Control and Cohort Studies

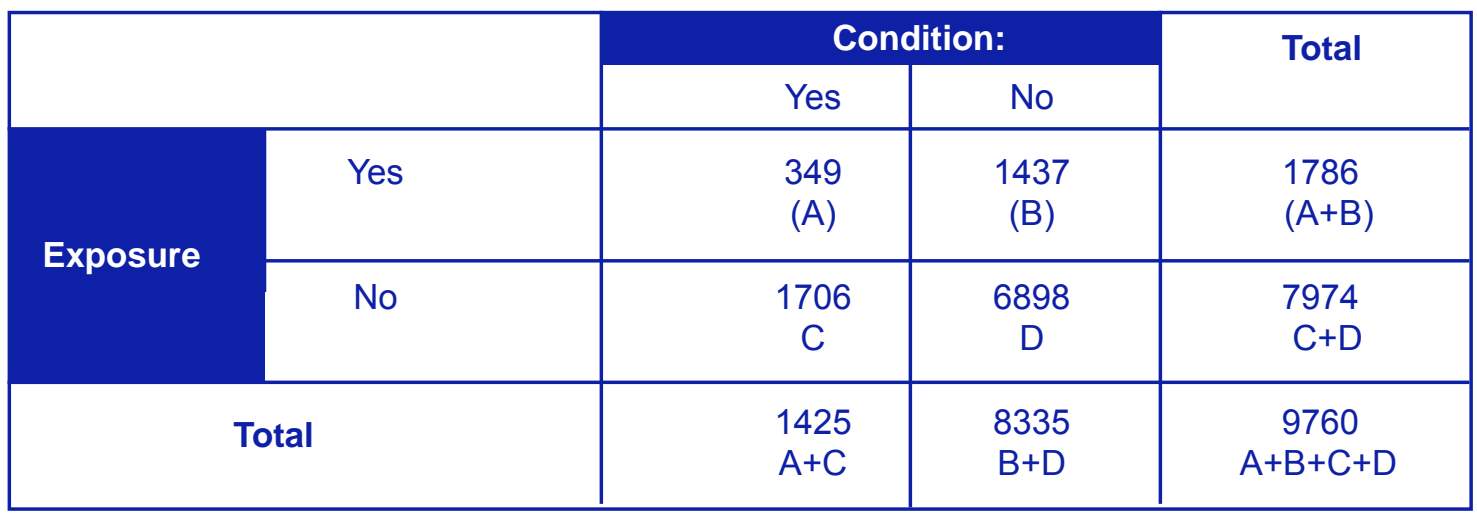

Data from a Cohort Study of periodontal disease and coronary heart disease conducted by DeStefano et al. (3). The unadjusted or raw relative risk (RR) is calculated as the ratio of the incidence of disease in the exposed group relative to unexposed group as follows:

$$
R R=\frac{A / A+B}{C / C+D}=\frac{(349)(1786)}{(1076)(7974)}=1.45
$$

Conclusion: Subjects with periodontal disease were $45 \%$ more likely to have coronary heart disease. 
One construct for discussing risk employs an illustration of the natural history of disease. ${ }^{8}$

According to this construct, several events precede and influence the observed mortality or morbidity outcome (e.g., death or diabetic complication). Prior to the development of symptoms (i.e., change in function, appearance or sensation), an individual experiences some pathological event or series of events recognized as the biologic onset of disease. Biologic onset is usually explained at the cellular or molecular level such as a change in host gene products, their expression or regulation. Such events are often predicated or influenced by genetic risk factors that are immutable to change and by environmental or behavioral exposures that are modifiable.

Periodontitis, for example, is a prevalent human disease with defined risk parameters that contributes to population morbidity in terms of edentulism and decreased oral function.9 Risk factors for destructive periodontitis have been extensively reviewed and include exposures such as specific bacterial pathogens, smoking and diabetes mellitus. $^{10,11}$ In addition, genetic factors based on polymorphisms and inflammatory responses have been recently identified. ${ }^{12,13}$ Epidemiologic surveys estimate that periodontitis affects roughly one third of adults. ${ }^{14-16}$ Although advanced periodontal destruction affects only one in eight persons, its prevalence increases to over one third among older individuals (55 to 65 years of age). Symptoms like tooth mobility, gingival tenderness, abscess formation and/or tooth loss generally occur in late stages of the disease; however, periodontitis for most persons remains an insidious but destructive inflammatory condition.

In the natural history of periodontitis, the chronic exposure to a pathogenic oral flora (e.g., Porphyromonas gingivalis, Bacteroides forsythus, Actinobacillus actinomycetemcomitans and Treponema denticola) remains a central pathophysiological event (Figure 2a)..$^{17,18}$

Figure 2. Chronology and events in the natural history of diseases.

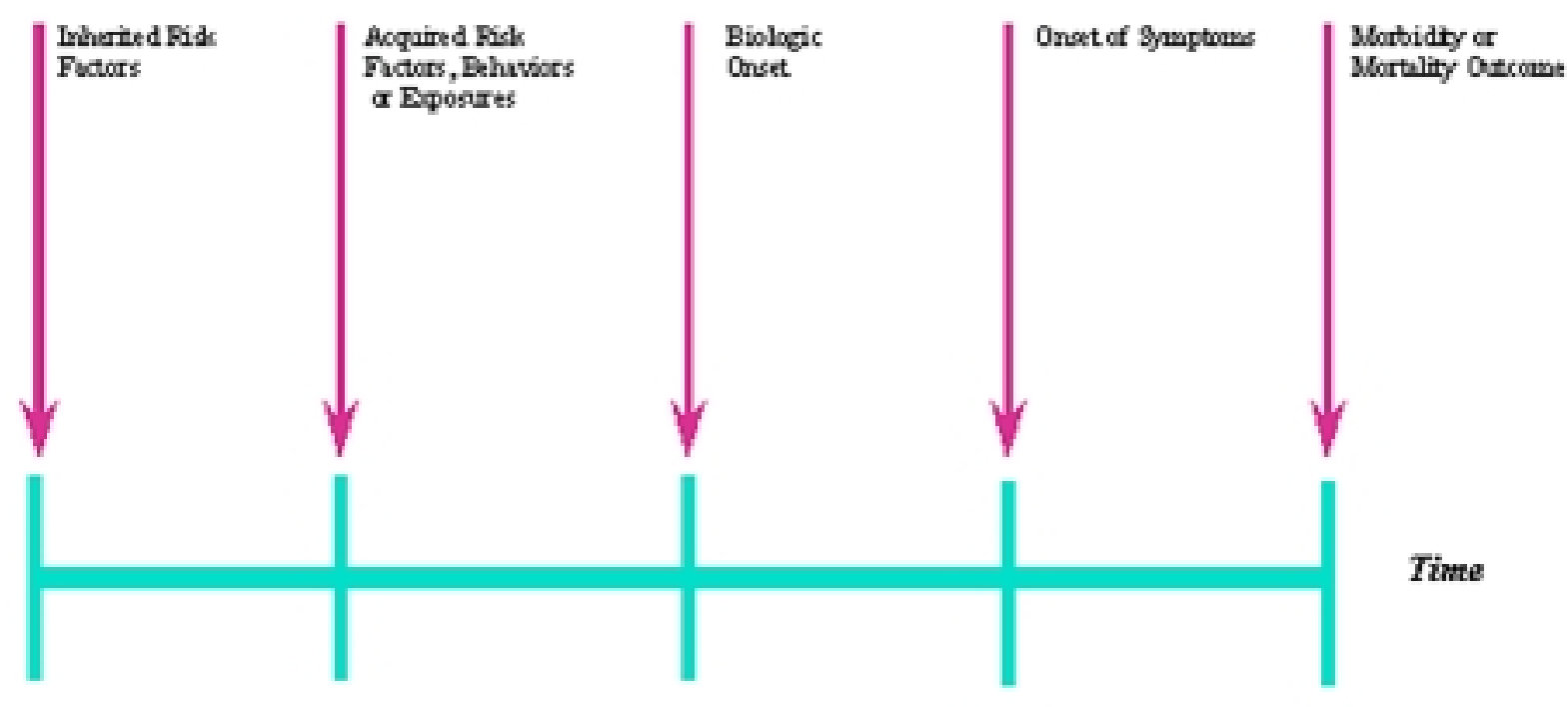

-Periodortitis
-Cardiovacular Disease
-Pre term Low Birth Weight 
Dental plaque serves as a microbial biofilm whereby pathogenic bacteria coexist and interact within a matrix-enclosed environment. The plaque biofilm exposes the host to bacterial cell surface components such as lipopolysaccharide (LPS) that are shed within the gingival sulcus in the form of outer membrane vesicles. These bacterial products both bombard and penetrate tissues coming into contact with a variety of host cells including monocytes and macrophages. Accordingly, LPS forms a complex with a host binding protein (i.e., lipopolysaccharide-binding protein or LPB) which in turn binds to CD14 receptors on monocytes and macrophages. ${ }^{19}$ These binding events lead to the expression and local release of immuno-inflammatory mediators like arachidonic acid metabolites (e.g., prostaglandin E2) and cytokines (e.g., interleukin$1 \mathrm{~b}$ and tumor necrosis factor $\mathrm{a}$ ). These biochemical-cellular interactions mark the biologic onset of the disease and set into motion catabolic events which culminate in periodontal tissue destruction (pocket formation, clinical attachment loss and alveolar bone loss). ${ }^{20}$

If one widens the perspective of the natural history of disease and looks at periodontitis as a potential exposure event itself, one begins to visualize risk within the context of periodontal medicine (Figure $2 b$ ).

Figure 2. Chronology and events in the natural history of diseases.

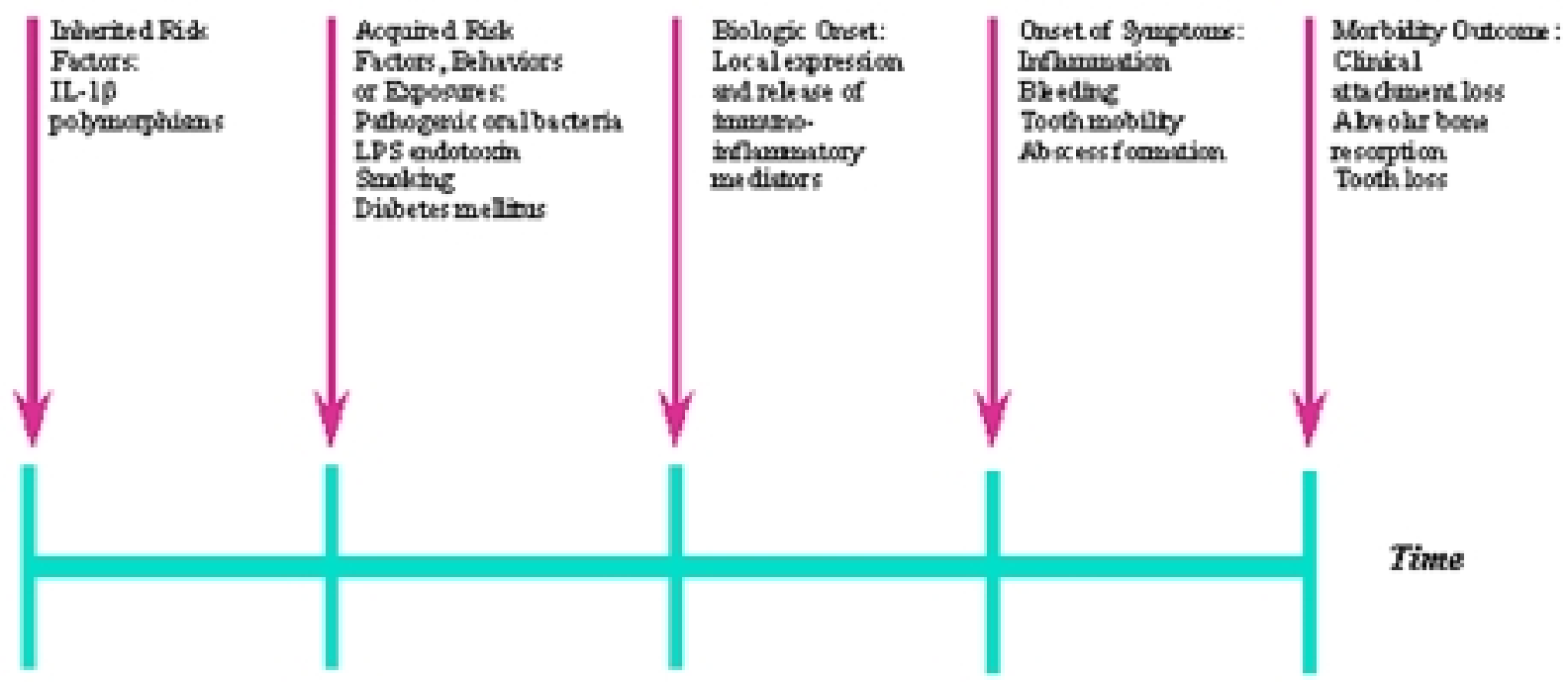

-Periodontitis

*Cardiovas ular Disease

- Pre term Low Birth Weight 
Figure 2. Chronology and events in the natural histcry of diseases.

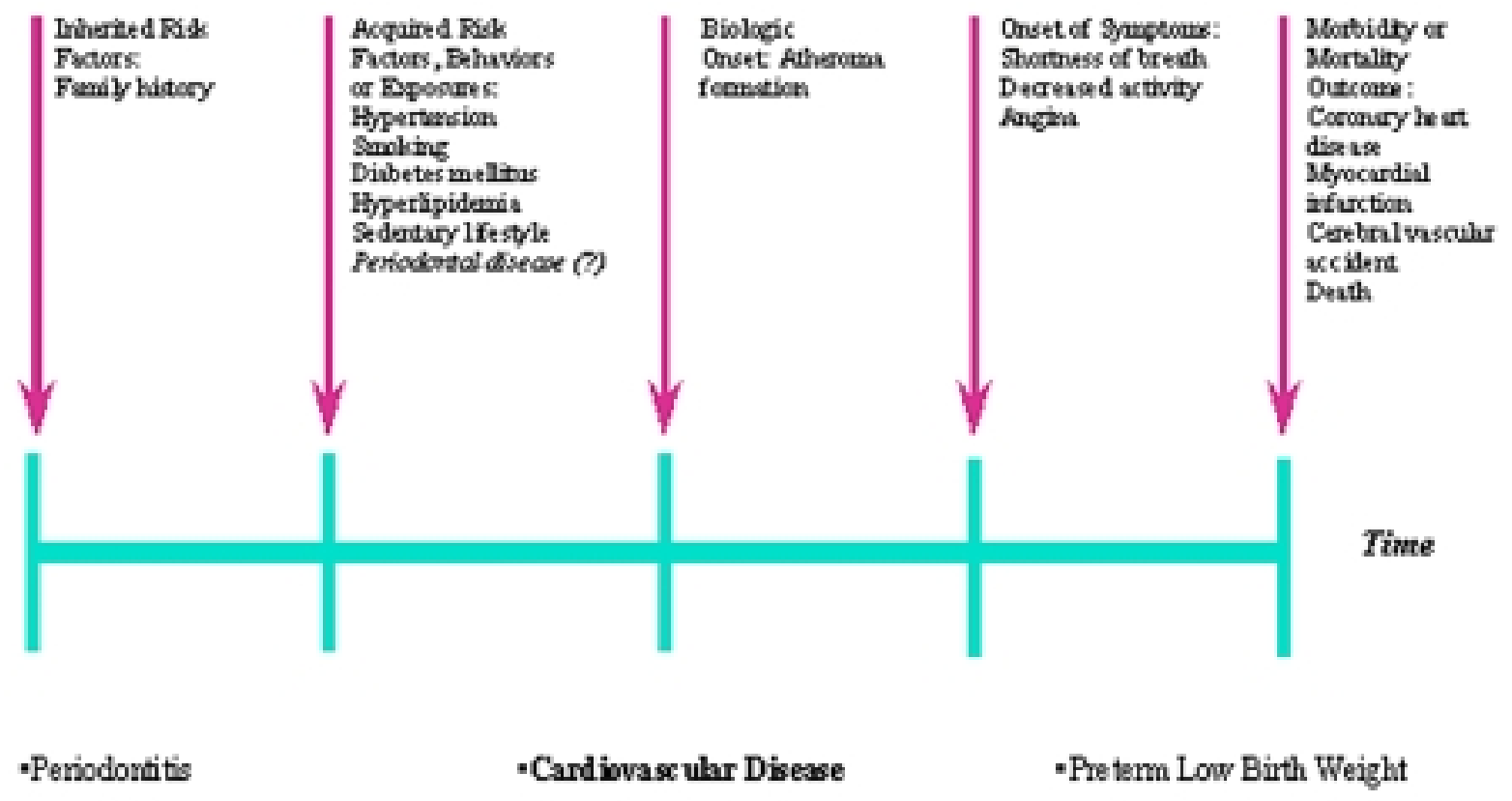

Fizure 2. Chronology and events in the natural history of diseases.

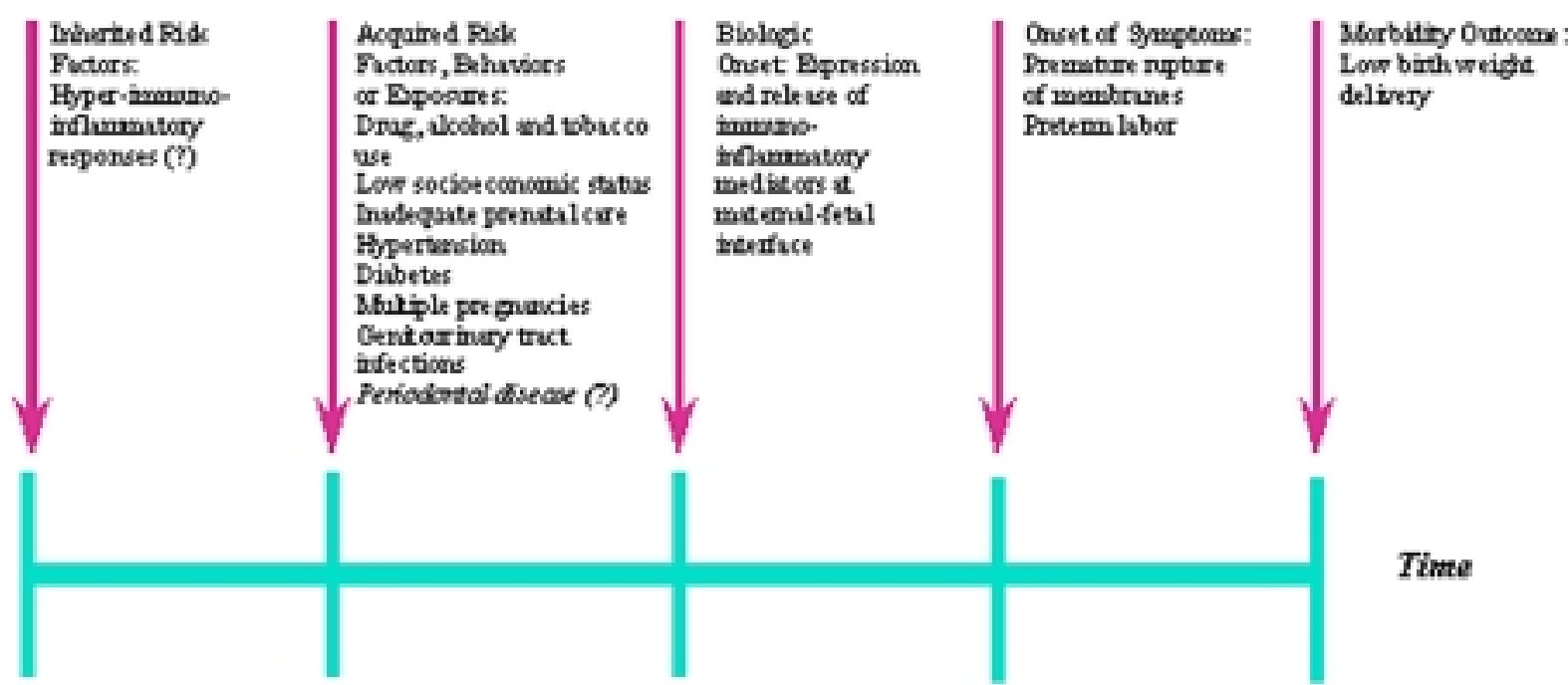

-Periodontitis

*Cardiovas ular Disease

-Preterm Low Birth Weight 


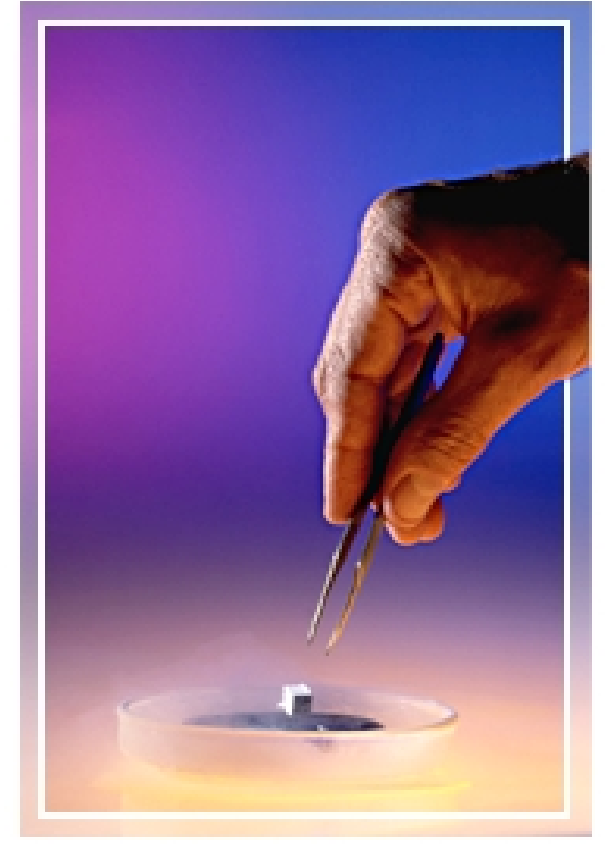

A central hypothesis of periodontal medicine states that periodontal infection presents a chronic inflammatory burden at the systemic level. In addition to their products, whole bacterial pathogens can enter local host tissues where pocket epithelial integrity has been lost (i.e., an ulceration measuring roughly $72 \mathrm{~cm} 2$ in the generalized advanced periodontitis patient). ${ }^{21}$ In addition, pathogens like $P$. gingivalis and $A$. actinomycetemcomitans have evolved virulence factors that allow for direct tissue invasion. ${ }^{22}$ Consequently, recurrent, transient bacteremias can occur in patients with periodontitis after daily, innocuous activities like tooth brushing and chewing. ${ }^{23-25}$ These systemic exposures to gram-negative pathogens, LPS and other products can trigger mediator expression and inflammatory events with consequences related to other organ systems. Prostaglandin E2, for instance, causes oxidative stress, smooth muscle contraction and low density lipoprotein (LDL) oxidation. Likewise, the cytokines IL-1b, TNFa and interleukin 6 (IL-6) can stimulate endothelial adhesion, hyperlipemia, metabolic wasting, hepatic release of acute phase reactants and connective tissue catabolism.

Many of these events have been implicated in the natural histories of systemic conditions like cardiovascular disease and preterm low birth weight. ${ }^{19}$ Interestingly, Slade et al. have analyzed cross sectional data from 12,949 dentate adults and 1,817 edentulous adults in the third National
Health and Nutrition Examination (NHANES III) survey and have demonstrated significant elevations in serum C-reactive protein (CRP), an acute phase reactant, occurring in subjects with periodontitis. ${ }^{26}$ These data indicate systemic release of inflammatory markers occurring in response to periodontal infections.

\section{The Emergence of Periodontal Medicine}

The notion that oral or periodontal infection can influence systemic health is not new to dentistry and has been proposed at various times throughout the centuries. Walter Miller again proposed this relationship in an 1891 commentary published in Dental Cosmos. ${ }^{27}$ Miller described the mouth as a "focus of infection" through which "microorganisms or their waste products obtain entrance to parts of the body adjacent to or remote from the mouth." This commentary listed several systemic diseases including gangrene, tuberculosis, meningitis, syphilis, septicemia and pneumonia, all thought to originate from an oral focus of infection. In a 1900 British Medical Journal report, William Hunter used the term "oral sepsis" and blamed it for causing "diseases such as tonsillitis, glandular swellings, middle ear infections, ulcerative endocarditis, empyema, meningitis and osteomyelitis." ${ }^{28}$ Other anecdotal reports over the subsequent three decades perpetuated the focal infection hypothesis in dentistry and medicine, and practitioners often referenced it when prescribing the prophylactic removal of teeth. ${ }^{29-31}$ However, when Cecil et al. monitored 156 patients with rheumatoid arthritis who underwent full-mouth extractions and noted that none improved, the evidence against the hypothesis began to mount. ${ }^{32}$ Finally, a 1952 editorial in the Journal of the American Medical Association dispelled any belief in the hypothesis since, "many patients with diseases caused by foci of infection have not been relieved of their symptoms by removal of the foci. Many patients with these same diseases have no evident focus of infection; also, foci of infection are as common in apparently healthy persons as those with disease." ${ }^{33}$

A landmark 1989 paper by Mattila and coworkers reintroduced the association between oral infection and systemic disease using sound, scientific methods. ${ }^{2}$ Later studies by DeStefano, Beck, Offenbacher and others have provided exciting support that periodontitis may confer independent 
risks for systemic conditions, in particular cardiovascular disease and preterm low birth weight.3-5 At the 1996 World Workshop in Periodontics, Offenbacher introduced the term, "periodontal medicine," as a discipline that focuses on validating this disease relationship and its biological plausibility in human populations and animal models. ${ }^{19}$ Instead of the traditional periodontal outcomes that are tooth or site-based (e.g., probing pocket depth or attachment levels), periodontal medicine concerns patient-based clinical outcomes such as disease morbidity or mortality events or implicated surrogate markers (e.g., serum inflammatory markers). As more studies, including randomized clinical trials, are conducted over the next decade, periodontal medicine may ultimately guide clinicians in making evidencebased decisions to improve not only patient oral health but also systemic health as well.

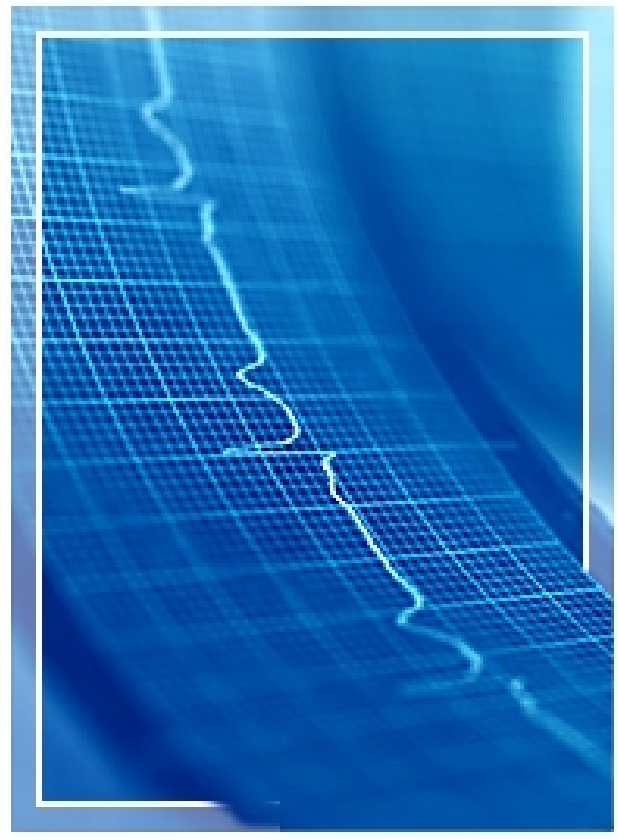

\section{Periodontal Medicine and Cardiovascular Disease}

According to recent statistics, cardiovascular disease causes $20 \%$ of deaths or 14 million worldwide annually. ${ }^{34}$ The disease's toll is especially pronounced in developed countries where it is the principal cause of death. Cardiovascular disease is synonymous with the term, atherosclerosis, a progressive, chronic condition marked by atheroma formation (i.e., fibrolipid deposition or plaques) in the intima of large and medium sized arteries. Severe atherosclerosis leads to reduction in the arterial lumen and predisposes to thrombosis, obstruction and ischemic phenomena.

Progressive disease may present in an individual as the signs and symptoms of coronary heart disease, or it may precipitate sudden events like myocardial infarctions or cerebral vascular accidents (stroke).

Interestingly, patients with cardiovascular disease and periodontitis share many of the same characteristics. Both conditions tend to occur more commonly in populations that are older and predominantly male, use tobacco products at higher rates, report higher stress levels and have lower educational status. ${ }^{35}$ Cardiovascular disease furthermore ranks as one of the most common systemic conditions affecting periodontitis patients. ${ }^{36,37}$ Syrjänen et al. found that oral infections (dental or periodontal) occurred more commonly in males with stokes versus age and community-matched controls. ${ }^{38}$ In addition, Kweider et al. compared subjects with and without periodontal disease and observed significant correlations with gingival index scores and elevations in patient fibrinogen and white blood cell counts (markers of thrombosis and infection respectively). ${ }^{39}$ These reports provided early and indirect evidence that a relationship between the diseases may occur in humans.

When Mattila and coworkers published results from their first case control study in 1989, a breakthrough on this association occurred. ${ }^{2}$ The Finnish group evaluated two series of subjects. The first series included 40 male patients (cases), aged 50 years or younger and admitted for acute myocardial infarction, and controls matched for age, gender, and community characteristics. In a second series, the investigative group matched 60 cases with controls, either men aged 60 years or younger, or females aged 65 years or younger. Oral infection for both studies was measured using a total dental index that included dental caries, endodontic disease and periodontitis components. Results indicated that cases exhibited worse dental health as compared to controls. Logistic regression analysis further indicated that poor dental health and myocardial infarction were associated with an odds ratio (OR) of 1.3 (i.e., subjects with poor dental health were 1.3 times more likely to experience myocardial infarction as compared to individuals with good dental health). This relationship occurred independent of known risk factors like age, total cholesterol, triglycerides, hypertension, smoking and the presence of diabetes. 
A second report by Mattila et al. followed shortly thereafter and evaluated the dental health of 100 subjects referred for diagnostic coronary angiography.40 Although no association between dental index score and coronary atheromatosis (i.e., artery narrowing or stenosis) was noted for females, the association was significant in males with an odds ratio of 1.4. The most recent investigation conducted by Mattila et al. has documented elevated risks for new myocardial infarction events or death occurring over a 7-year monitoring period for individuals with poor dental index scores (hazard ratio or $\mathrm{HR}=1.2$ ). ${ }^{41}$

While the studies listed above used the total dental index to measure oral health status, the results reflect not only periodontitis but also other discreet and independent oral infections. DeStefano et al. focused on the contribution of periodontitis and analyzed coronary heart disease and mortality outcomes in nearly 10,000 subjects followed for 14 years longitudinally in the NHANES I study. ${ }^{3}$ Periodontitis for this cohort study was assessed with the periodontal index. Overall, subjects with periodontitis had a $25 \%$ increased risk for coronary heart disease relative to those with minimal periodontal disease. This association occurred after adjustments for potential confounders like age, sex, race, education, marital state, systolic blood pressure, total cholesterol levels, body mass index, diabetes, physical activity, alcohol consumption, poverty and cigarette smoking. For males younger than 50 years, periodontitis more strongly affected the incidence of coronary heart disease with a relative risk of 1.72 .

Genco et al. tested a similar hypothesis in 1,372 Native Americans of the Gila River Indian Community, a cohort with a high prevalence of diabetes mellitus. ${ }^{42}$ The investigators evaluated periodontal status at baseline using dental radiographs and assessed the onset of cardiovascular disease over a period of 10 years or longer using electrocardiograms. Though baseline bone height was predictive of cardiovascular disease among all age groups, it failed to remain significant in a multivariate analysis. However, individuals aged 60 years or older with periodontal bone loss were 2.68 times more likely to develop cardiovascular disease after adjusting for gender and duration of diabetes.

Joshipura and coworkers from Harvard monitored the health status of 44,119 males participating in the Health Professionals Follow-up Study (HPFS) over a 6-year period. ${ }^{43}$ Subjects self-reported tooth loss, dietary histories and the onset of coronary heart disease using mailed questionnaires. Overall, no significant association between tooth loss and coronary heart disease $(R R=1.04$, $\mathrm{Cl}=0.86,1.25)$ was detected after controlling for age, body mass, exercise, smoking habits, alcohol consumption, vitamin $E$ and family history of myocardial infarction before age 60 . Males with 0 to 10 teeth, however, represented a significant relative risk of 1.4 when compared to males with 25 or more teeth. Stratification of tooth loss by periodontal history confirmed that this association was limited to males with periodontal disease.

Beck and coworkers at the University of North Carolina further assessed the association using cohort data collected over 18 years in the Dental Longitudinal Study (DLS) sponsored by the Department of Veterans Affairs. ${ }^{4}$ Subjects numbered 1,147 and were healthy males included in a larger, longitudinal health outcomes study, the Normative Aging Study (NAS). At baseline, periodontal status was assessed using intraoral radiographs, and a mean bone loss score (\%) was calculated for each subject. Subjects were then classified as having either high or low baseline bone loss scores ( $>20 \%$ or $<20 \%$ respectively). Over the monitoring period, cases with cardiovascular disease were identified on the basis of nonfatal myocardial infarction, angina pectoris, coronary heart disease death or stroke. The results indicated that high alveolar bone loss scores were associated with incidence odds ratios of 1.5, 1.8 and 2.8 for total coronary heart disease, fatal coronary heart disease and stroke respectively (adjusting for age, systemic blood pressure and other known risk factors). In addition, the cumulative incidence for all three cardiovascular disease outcomes increased linearly with increasing severity of bone loss scores in subjects. These findings support a strong and specific association in which the exposure to periodontal infection follows a dose-effect relationship with cardiovascular disease. The North Carolina group recently presented preliminary dental findings from an ongoing population study of cardiovascular disease called the Atherosclerosis Risk in Communities (ARIC) study. ${ }^{44}$ Six hundred and fifty-six subjects were categorized as having coronary heart disease, exhibiting subclinical atherosclerosis (i.e., carotid intimal-medial wall thickening detected with $B$ mode ultrasound) or being healthy controls. Periodontal disease as defined with attach- 
ment loss was significantly more severe among the coronary heart disease and subclinical atherosclerosis subjects as compared to healthy controls.

Lately, data regarding the periodontal microbial challenge support the biological plausibility of the associations seen in human population studies. Hertzberg et al. have reported that two oral microbes, Streptococcus sanguis and P. gingivalis, express a collagen-like platelet aggregationassociated protein that can stimulate thrombotic events. ${ }^{45,46}$ Genco et al. presented preliminary data that suggest an odds ratio of 2.8 for subjects harboring $\mathrm{P}$. gingivalis in periodontal pockets and exhibiting a myocardial infarction. ${ }^{47}$ In addition,
Zambon et al. recently isolated DNA sequences specific for periodontal pathogens like $P$. gingivalis and $A$. actinomycetemcomitans from human atheroma specimens using polymerase chain reaction (PCR) techniques. ${ }^{48}$ Other nonperiodontal infectious agents like Clamydia pneumoniae, Helobacter pylori, herpes simplex and cytolomegalovirus have been previously detected in atheromatous lesions using similar methods, and further support an infectious etiology for cardiovascular disease. ${ }^{49}$

(Figure 3) summarizes a current model for the periodontitis-cardiovascular disease association derived from these collective investigations.

Figure 3. Proposed model for the associations between pe riodontal disease and carciovascular disease and pretemn lowbirth weight

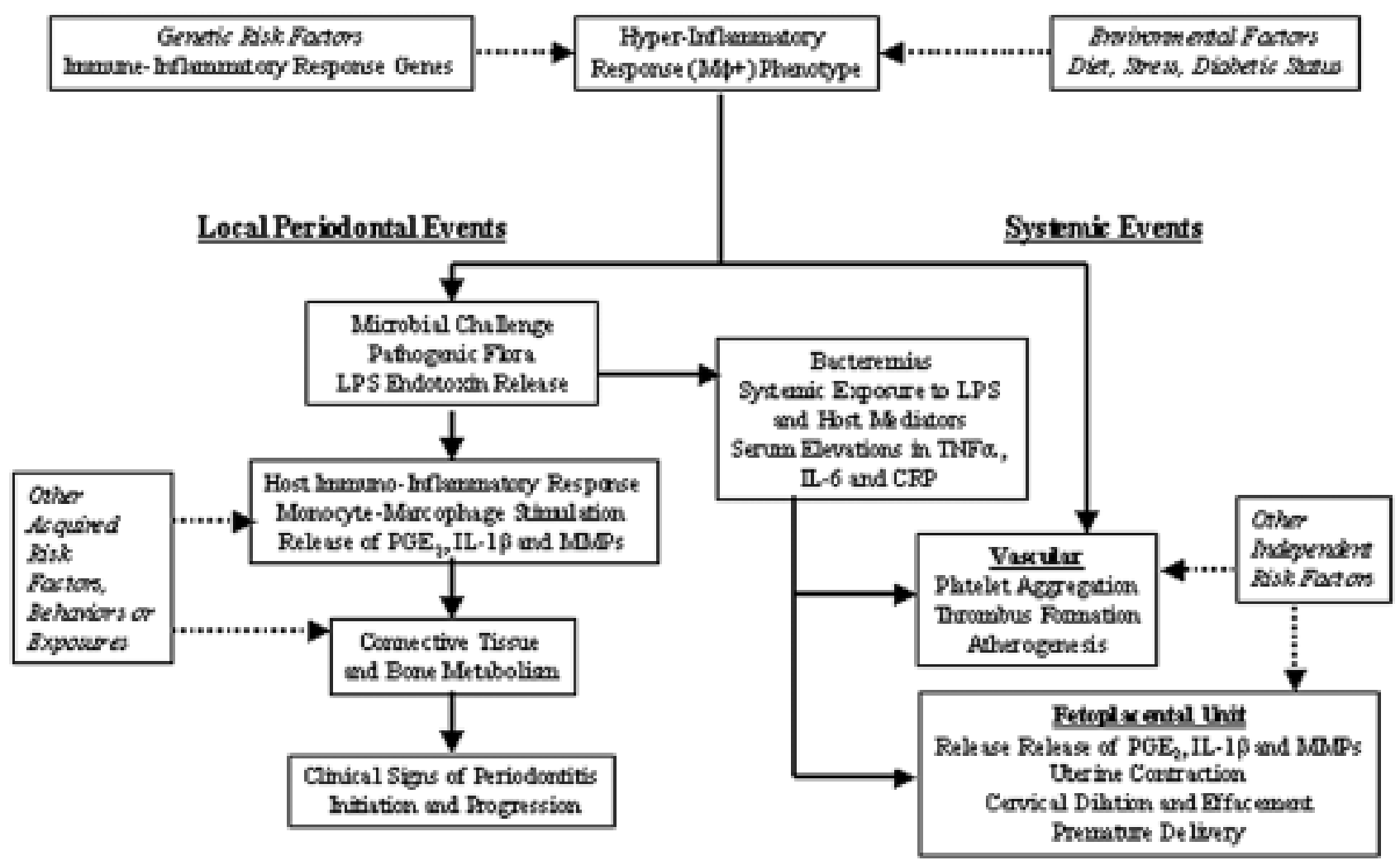

12

The Journal of Contemporary Dental Practice, Volume 1, No. 1, Fall Issue, 1999 
Immune and inflammatory response genes and environmental factors such as diet and stress interplay to influence monocyte/lymphocyte responses and influence the expression of a hyper-inflammatory phenotype. This phenotype predisposes the individual for both atherosclerosis and periodontitis. While atherosclerotic lesion formation and thrombotic events may occur independently in an individual, they may be exacerbated by the systemic microbial and LPS exposures posed by periodontitis and its concurrent inflammatory mediator barrage. Thus, periodontal infection may influence systemic events like platelet aggregation, thrombus formation and atherogenesis thereby increasing the risk for atherosclerosis, coronary heart disease and stroke.

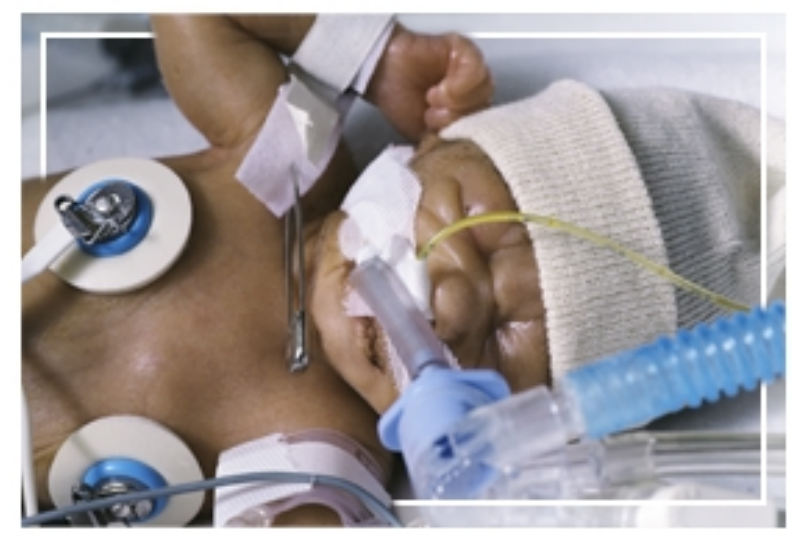

\section{Periodontal Medicine and Preterm Low Birth Weight}

Premature low birth weight (PLBW) is defined as an adverse pregnancy outcome where the infant weighs less than $2,500 \mathrm{~g}$ and where the birth occurs less than 37 weeks of gestational age..$^{50}$ Overall, PLBW has a $10 \%$ annual incidence rate in the U.S. but accounts for more than $60 \%$ of the infant mortality not attributable to anatomic or chromosomal congenital defects. ${ }^{51}$ Of the preterm births that spontaneously result from premature rupture of membranes or preterm labor, a small subset exhibit intrauterine growth restriction defined as less than the tenth percentile for gestational age, or very low birth weight defined as less than $1,500 \mathrm{~g}$ (usually less than 37 weeks). The societal burden of PLBW can be measured in terms of both economic and morbidity outcomes. Annual intensive care unit costs for treating PLBW infants total more than $\$ 5$ billion. ${ }^{52}$ Respiratory distress, cerebral palsy and learning disorders are among the long-term disabilities of PLBW. Over the past two decades unfortunately, prenatal care intervention strategies have failed to diminish these rates despite decreases in overall infant mortality.

Known risk factors for PLBW include maternal age (less than 17 years or more than 34 years), drug, alcohol and tobacco usage, African American race, low socioeconomic status, inadequate prenatal care, hypertension, diabetes, multiple pregnancies and genitourinary tract infections. ${ }^{53}$ With regard to this last listed factor, vaginal colonization with Bacteroides species (bacterial vaginosis) increases PLBW rates by $40-$ $60 \%{ }^{54,55,56}$ Hillier et al. however have reported that $18-49 \%$ of placentas with inflamed chorioamnionic membranes (chorioamnionitis) have negative bacterial cultures. ${ }^{57}$ These findings prompted Gibbs et al. to speculate that genitourinary tract infections may indirectly cause PLBW via the translocation of bacterial products like LPS from the vaginal tract to the fetoplacental unit or by maternally produced inflammatory mediators. ${ }^{58}$ Offenbacher and coworkers first questioned whether periodontal infection could mediate PLBW via these same indirect mechanisms and tested the hypothesis in the pregnant hamster model. ${ }^{59}$ A subcutaneous chamber model was selected for inoculating or challenging animals with a specific periodontal pathogen. This model originally described by Genco and Arko for studying gonorrheal infections, ${ }^{60}$ produces a non-disseminating, chronic, subclinical infection similar to periodontitis. Following subcutaneous implantation of the stainless steel chambers, female hamsters were randomized for one of four groups. One experimental group received heat-killed $P$. gingivalis (day -14 ) followed by a live challenge of P. gingivalis (day 8). Two other experimental groups received either heat-killed or live organisms alone. A fourth group received vehicle alone and served as negative controls. All animals were mated on day 0 and followed until parturition (approximately 19 days) for pregnancy outcomes including fetal weights, viability and resorptions. The results indicated that animals receiving either heat-killed plus live $P$. gingivalis or live P. gingivalis alone exhibited $15-18 \%$ decreases in fetal weight. Hence, pretreatment or immunization with heat-killed organisms failed to confer protection from lower fetal weights. Although these low-grade infections did not induce fever or malaise among the animals, they did produce elevations of PGE2 and TNFa in fluid aspirated from the chambers. 
Following these promising initial results, Offenbacher and coworkers extended their experiments to include pregnant hamsters with experimental periodontitis. ${ }^{61}$ Four groups of animals were fed either control diet or plaque-promoting chow for 8 weeks to induce experimental periodontitis prior to mating. In addition, one control diet group and one plaque-promoting chow group were challenged with exogenous $P$. gingivalis by gastric gavage. No significant effects of $P$. gingivalis challenge for either diet condition was detected. In contrast, both groups of animals fed the plaque-promoting diet (i.e., with or without exogenous $\mathrm{P}$. gingivalis challenge) exhibited evidence of periodontitis and significantly smaller mean litter weights. In addition, animals with the diet-induced periodontitis demonstrated significant elevations in intra-amniotic fluid concentrations of PGE2 and TNFa, immuno-inflammatory mediators that can induce uterine contraction, cervical dilation, labor and abortion. ${ }^{58}$

To investigate an association in humans, Offenbacher et al. conducted a case control study of 124 pregnant or postpartum mothers. ${ }^{5}$ PLBW cases were identified as $<2,500 \mathrm{~g}$ along with gestational age $<37$ weeks due to preterm labor or premature rupture of membranes. Controls were mothers with normal birth weight (NBW) infants. Periodontal status was determined using clinical attachment levels and extent scores. PLBW and primiparous (first pregnancy) PLBW cases exhibited significantly more clinical attachment loss as compared to NBW controls. Multivariate logistic regression models controlling for other risk factors and covariates detected a significant, strong association between periodontal disease (i.e., $60 \%$ or more of sites with $>3 \mathrm{~mm}$ attachment loss) and PLBW with adjusted odds ratios of 7.5-7.9. Indeed, the odds ratios for periodontal disease were numerically higher than other known risk factors like alcohol use, tobacco and maternal age.

A second case control study focused on differences in the local host response and periodontal flora between cases and controls. ${ }^{62}$ Accordingly, Offenbacher and investigators at North Carolina selected 25 PLBW cases and 15 NBW controls. Gingival crevicular fluid (GCF) was collected and assayed for concentrations of PGE2. In addition, subgingival plaque samples were obtained from mothers and analyzed for four periodontal pathogens using checkerboard DNA-DNA hybridization techniques. Whereas mean GCF-
PGE2 levels for NBW controls were $62.6 \mathrm{ng} / \mathrm{ml}$, mean GCF-PGE2 levels for PLBW cases were $131.4 \mathrm{ng} / \mathrm{ml}$ and significantly elevated. In addition, a significant inverse relationship was observed between the log GCF-PGE2 and birth weight among primiparious mothers such that smaller and more premature infants were born to mothers with higher GCF-PGE2 levels. Higher levels of the pathogens, P. gingivalis, B. forsythus, A. actinomycetemcomitans and $T$. denticola were detected among the PLBW cases; however, these were not statistically significant.

Recent data from the North Carolina group further clarifies the microbial dimension of the periodontitis-PLBW association. Fetal cord blood samples from 21 PLBW and 39 NBW infants were collected and analyzed for the presence of IgM specific antibody against 13 periodontal pathogens using checkerboard immunoblotting. ${ }^{63}$ While $17.9 \%$ of fetal cord blood samples from NBW infants tested positive for IgM directed against the tested pathogens, $33.3 \%$ of PLBW samples tested positive. Overall, IgM was most commonly specific for Campylobacter rectus followed by $\mathrm{P}$. gingivalis and Fusobacterium nucleatum. These early data indicate that fetal cord blood IgM directed against specific periodontal pathogens could be detected in both PLBW and NBW infants; nevertheless, these specific fetal immune responses to periodontal pathogens provide direct evidence that maternal periodontal infection can provide a systemic challenge to the fetus in utero.

These cumulative data have allowed Offenbacher and coworkers to propose the following model of periodontal infection associated prematurity (Figure 3). Periodontitis serves as a remote infection that seeds bacteria, LPS and mediators into the systemic circulation. At the fetoplacental unit, these chemical stimuli trigger the local release of inflammatory mediators like PGE2, IL$1 \mathrm{~b}, \mathrm{TNFa}$ and matrix metalloproteinases (MMPs) which cause uterine contraction, cervical dilation, cervical effacement and premature delivery.

\section{Summary}

Table 3 summarizes the reviewed human studies conveying associations between periodontal disease and cardiovascular disease or low birth weight. The cumulative data suggest that patients with periodontal disease appear to be two times more likely to exhibit cardiovascular disease and seven times more likely to bear low birth weight infants. These data have been 
derived from cross sectional and cohort studies, their analyses occurred on a post-hoc basis or secondary to other objectives, and the lines of evidence are moderate in terms of quality and weight. We currently do not know whether there are direct cause-effect relationships between periodontal disease and the two systemic conditions. Further investigations testing these hypotheses a priori in larger populations are needed to validate that these associations are consistent, strong, specific, chronologically correct, dose-related and biologically plausible. Also, since randomized clinical or intervention trials have yet to be conducted, we still do not know whether periodontal treatment can prevent the occurrence of myocardial infarction or preterm labor in patients. There is initial evidence that periodontal treatment can have an effect systemically. Ebersole et al. have demonstrated that periodontal debridement can lower serum levels of $\mathrm{C}$-reactive protein, an acute phase reactant produced by the liver in response to inflammation. ${ }^{64}$ In a separate population study, Ridker and coworkers have shown that low serum levels of C-reactive protein are associated with reduced risks for myocardial infarction. ${ }^{65}$ These early studies indirectly support the hypothesis that periodontal treatments can potentially reduce the likelihood of systemic disease.

Table 3. Summary of human studies suggesting associations between periodontal disease and cardiovascular disease or preterm low birth weight.

\begin{tabular}{|c|c|c|c|c|}
\hline & $\begin{array}{l}\text { Citation and } \\
\text { Reference }\end{array}$ & $\begin{array}{l}\text { Study } \\
\text { Design }\end{array}$ & Association & Measure \\
\hline \multirow[t]{7}{*}{$\begin{array}{l}\text { Cardiovascular } \\
\text { Disease }\end{array}$} & Mattila et al.1989 (2) & $\begin{array}{l}\text { Case } \\
\text { Control }\end{array}$ & $\begin{array}{l}\text { Total dental index and myocardial } \\
\text { infarction }\end{array}$ & $\mathrm{OR}=1.3$ \\
\hline & Mattila et al. $1993(40)$ & $\begin{array}{l}\text { Case } \\
\text { Control }\end{array}$ & $\begin{array}{l}\text { Total dental index and coronary } \\
\text { atheromatosis }\end{array}$ & OR=1.4 (males) \\
\hline & Mattila et al.1995 (41) & Cohort & $\begin{array}{l}\text { Total dental index and new } \\
\text { myocardial infarctions or death }\end{array}$ & $\mathrm{HR}=1.2$ \\
\hline & DeStefano et al1993(3) & Cohort & $\begin{array}{l}\text { Periodontal index and hospital } \\
\text { admission or death due to } \\
\text { coronary heart disease }\end{array}$ & $\begin{array}{l}\mathrm{RR}=1.2 \text { (overall) } \\
\mathrm{RR}=1.72 \text { (males } \\
\text { younger than } 50 \\
\text { years) }\end{array}$ \\
\hline & Beck et al.1996 (4) & Cohort & $\begin{array}{l}\text { Alveolar bone loss and newOR=1,5 } \\
\text { coronary heart disease } \\
\text { Alveolar bone loss and fatal } \\
\text { coronary heart disease } \\
\text { Alveolar bone loss and cerebral } \\
\text { vascular accidents }\end{array}$ & $\begin{array}{l}\mathrm{OR}=1.9 \\
\mathrm{OR}=2.8\end{array}$ \\
\hline & Joshipura et al.1996 (43) & Cohort & $\begin{array}{l}\text { Tooth loss in males with } \\
\text { periodontal disease and } \\
\text { coronary heart disease }\end{array}$ & $\begin{array}{l}\mathrm{RR}=1.0 \text { (overall) } \\
\mathrm{RR}=1.4 \text { (males } \\
\text { with } 0-10 \text { teeth } \\
\text { versus males } \\
\text { with }>25 \text { teeth }\end{array}$ \\
\hline & Genco et al.1997 (42) & Cohort & $\begin{array}{l}\text { Alveolar bone loss and new } \\
\text { coronary heart disease }\end{array}$ & $\mathrm{OR}=2.7$ \\
\hline $\begin{array}{l}\text { Preterm Low } \\
\text { Birth Weight }\end{array}$ & Offenbacher et al.1996(5) & $\begin{array}{l}\text { Case } \\
\text { Control }\end{array}$ & $\begin{array}{l}\text { Clinical attachment loss } \\
\text { (extent) and preterm low } \\
\text { weight births }\end{array}$ & $\mathrm{OR}=7.5$ \\
\hline
\end{tabular}


The emerging discipline of periodontal medicine will continue to gather higher levels of evidence on these risk associations and conduct the needed intervention trials. Meanwhile, dental clinicians must be highly appraised of the available information on these associations and understand the strengths and weaknesses of the data.

Secondly, clinicians need to offer patients up-todate and accurate information on these potential relationships, especially among patients with diagnosed systemic disease or patients with other known risk factors like family histories, smoking or diabetes. Thirdly, dental clinicians need to strengthen their collaborations and networks with medical colleagues to appropriately diagnose and care for complex, at risk patients. In the future, the discipline of periodontal medicine may ultimately assist dental clinicians in making treatment decisions that not only improve oral health but also reduce the likelihood of systemic diseases and improve patient lives.

\section{References}

1. Skolbekken JA. The risk epidemic in medical journals. Soc Sci Med 1995;40: 291-305.

2. Mattila K, Neiminen M, Valtonen $\mathrm{V}$, et al. Association between dental health and acute myocardial infarction. $\mathrm{Br}$ Med J 1989;298: 779-782.

3. DeStefano F, Anda RF, Kahn HS, et al. Dental disease and risk of coronary heart disease and mortality. Br Med J 1993;306: 688-691.

4. Beck J, Garcia R, Heiss G, et al. Periodontal disease and cardiovascular disease. J Periodontol 1996;67: 1123-37.

5. Offenbacher S, Katz V, Fertik G, et al. J. Periodontal infection as a possible risk factor for preterm low birth weight. J Periodontol 1996;67: 1103-1113.

6. Kleinbaum DG, Kupper LL, Morgenstern H. Epidemiological Research: Principles and Quantitative Methods. London: Lifetime Learning Publications; 1982.

7. Eisen GM, Sandler RS, Wurzelmann JI, et al. Evaluating risk: a primer for gastroenterologists. Am J Gastroenterol 1995;90: 704-707.

8. Hennekens CH, Buring JE, Mayrent SL. Epidemiology in Medicine. Boston: Little, Brown and Company; 1987.

9. Oliver RC, Brown LJ. Periodontal diseases and tooth loss. Periodontol 2000 1993;2: 117-127.

10. Genco RJ. Current view of risk factors for periodontal diseases. J Periodontol 1996;67: 1041-1049.

11. Salvi GE, Lawrence HP, Offenbacher S, et al. Influence of risk factors on the pathogenesis of periodontitis. Periodontol 2000 1997;14: 173-201.

12. Kornman KS, Crane A, Wang HY, et al. The interleukin-1 genotype as a severity factor in adult periodontal dis ease. J Clin Periodontol 1997;24: 72-7.

13. Hart TC, Kornman KS. Genetic factors in the pathogenesis of periodontitis. Periodontol 2000 1997;14: 202-15.

14. Brown LJ, Brunelle J, Kingman A. Periodontal status in the United States, 1981-91. Prevalence, extent and demographic variations. J Dent Res 1996;75: 672-683.

15. Brown LJ, Oliver RC, Löe H. Periodontal diseases in the U.S. in 1981: Prevalence, severity, extent, and the role in tooth mortality. J Periodontol 1989;60: 363-370.

16. Brown LJ, Oliver RC, Löe H. Evaluating periodontal disease status of U.S. employed adults. J Am Dent Assoc 1990;121: 226-232.

17. Darveau RP, Tanner A, Page RC The microbial challenge in periodontitis. Periodontol 2000 1997;14: 12-32.

18. Socransky SS, Haffajee AD, Cugini MA, et al. Microbial complexes in subgingival plaque. J Clin Periodontol 1998;25: 134-144.

19. Offenbacher S. Periodontal diseases: pathogenesis. Ann Periodontol 1996;1: 821-878.

20. Page RC, Offenbacher S, Schroeder HE, et al. Advances in the pathogenesis of periodontitis: summary of developments, clinical implications and future directions. Periodontol 2000 1997;14: 216-248.

21. Page RC. The pathobiology of periodontal diseases may affect systemic diseases: inversion of a paradigm. Ann Periodontol 1998;3: 108-120.

22. Haffajee AD, Socransky SS. Microbial etiological agents of destructive periodontal diseases. Periodontol 2000 1994;5: 78-111.

23. Murray M, Moosnick F. Incidence of bacteremias in patients with dental plaque. J Lab Clin Med 1941;26: 801-802.

24. Silver JG, Martin AW, McBride BC. Experiment transient bacteremias in human subjects with varying degrees of plaque accumulation and gingival inflammation. J Clin Periodontol 1980;4: 92-99.

25. Sconyers JR, Crawford JJ, Moriarty JD. Relationship of bacteremia to toothbrushing in patients with periodontitis. J Am Dent Assoc 1973;87: 616-622.

26. Slade GD, Pankow JS, Offenbacher S, et al. Acute-phase inflammatory response to oral and systemic conditions. J Dent Res 1999;78: 2192 (Abstract).

27. Miller WD. The human mouth as a focus of infection. Dental Cosmos 1891;33: 689-713.

16

The Journal of Contemporary Dental Practice, Volume 1, No. 1, Fall Issue, 1999 
28. Hunter W. Oral sepsis as a cause of disease. Br Med J 1900;1: 215-216.

29. Billings F. Chronic focal infections and their etiologic relations to arthritis and nephritis. Arch Inter Med 1912;9: 484-498.

30. Mayo CH. Focal infection of dental origin. Dental Cosmos 1922;64: 1206-1208.

31. Galloway CE. Focal infection. Am J Surg 1931;14: 643-645.

32. Cecil RL, Angevine D M. Clinical and experimental observations on focal infection with an analysis of 200 cases of rheumatoid arthritis. Ann Intern Med 1938;12: 577-584.

33. Editorial. JAMA 1952;150: 490.

34. Tunstall-Pedoe H, Kuulasmaa K, Amouyel P, et al. Myocardial infarction and coronary deaths in the World Health Organization MONICA Project. Registration procedures, event rates, and case-fatality rates in 38 populations from 21 countries in four continents. Circulation 1994;90: 583-612.

35. Beck JD, Offenbacher S, Williams R, et al. Periodontitis: a risk factor for coronary heart disease?. Ann Periodontol 1998;3: 127-141.

36. Umino M, Nagao M. Systemic diseases in elderly dental patients. Int Dent J 1993;43: 213-218.

37. Nery EB, Meister F Jr, Ellinger RF, et al. Prevalence of medical problems in periodontal patients obtained from three different populations. J Periodontol 1987;58: 564-568.

38. Syrjänen J, Peltola J, Valtonen V, et al. Dental infections in association with cerebral infarction in young and middle-aged men. J Intern Med 1989;225: 179-184.

39. Kweider M, Lowe GD, Murray GD, et al. Dental disease, fibrinogen and white cell count; links with myocardial infarction?. Scott Med J 1993;38: 73-74.

40. Mattila KJ, Valle MS, Nieminen MS, et al. Dental infections and coronary atherosclerosis. Atherosclerosis 1993;103: 205-211.

41. Mattila KJ, Valtonen VV, Nieminen M, et al. Dental infection and the risk of new coronary events: prospective study of patients with documented coronary artery disease. Clin Inf Dis 1995;20: 588-592.

42. Genco R, Chadda S, Grossi S, et al. Periodontal disease is a predictor of cardiovascular disease in a Native American population. J Dent Res 1997;76: 3158 (Abstract).

43. Joshipura KJ, Rimm EB, Douglass CW, et al. Poor oral health and coronary heart disease. J Dent Res 1996;75: 1631-1636.

44. Offenbacher S, Beck JD, Elter J, et al. Periodontal Status of cardiovascular disease subjects. J Dent Res 1999;78: 2190 (Abstract).

45. Herzberg MC, Weyer MW. Dental plaque, platelets, and cardiovascular diseases. Ann Periodontol 1998;3: 151-160.

46. Erickson PR. Herzberg MC. The Streptococcus sanguis platelet aggregation-associated protein. Identification and characterization of the minimal platelet-interactive domain. J Biol Chem 1993;268: 1646-1649.

47. Genco RJ, Wu TJ, Grossi SG, et al. Periodontal microflora related to the risk for myocardial infarction. J Dent Res 1999;78: 2811 (Abstract).

48. Zambon JJ, Haraszthy VI, Grossi S, et al. Identification of periodontal pathogens in atheromatous plaques. J Dent Res 1997;76: 3159 (Abstract).

49. Buja LM, Does atherosclerosis have an infectious etiology. Circulation 1996;94: 872-873.

50. World Health Organization, Expert Committee on Maternal and Child Health. Public Health Aspect of Low Birth Weight. Geneva: Switzerland; WHO technical report series, no. 27, 1950.

51. National Center for Health Statistics. Advance Report of Final Natality Statistics, 1991. Monthly vital statistics report, vol. 42, suppl. Hyattsville, MD: Public Health Service; 1993.

52. National Center for Health Statistics. Health, United States, 1982. Washington, DC: U.S. Government Printing Office; DHHS publication (PHS) 83-1232, December 1982.

53. Committee to Study the Prevention of Low Birthweight, Division of Health Promotion and Disease Prevention, Institute of Medicine. Preventing Low Birthweight. Washington, DC: National Academy Press; 1985.

54. Patrick MJ. Influence of maternal renal infection on the foetus and infant. Arch Dis Child 1967;42: 208-213.

55. Minkoff H, Grunebaum AN, Schwarz RH, et al. Risk factors for prematurity and premature rupture of membranes: a prospective study of the vaginal flora in pregnancy. Am J Obstet Gynecol 1984;150: 965-972.

56. McDonald HM, O'Loughlin JA, Jolley $\mathrm{P}$, et al. Vaginal infection and preterm labour. Br J Obstet Gynaecol 1991;98: 427-435.

57. Hillier SL, Martius J, Krohn M, et al. A case-control study of chorioamnionic infection and histologic chorioamnionitis in prematurity. N Eng J Med 1988;319: 972-978.

58. Gibbs RS, Romero R, Hillier SL, et al. A review of premature birth and subclinical infection. Am J Obstet Gynecol 1992;166: 1515-1528.

59. Collins JG, Windley HW 3rd, Arnold RR, et al. Effects of a Porphyromonas gingivalis infection on inflammatory mediator response and pregnancy outcome in hamsters. Infect Immun 1994;62: 4356-4361.

60. Genco CA, Arko RJ. Animal chamber models for study of host-parasite interactions. Methods Enzymol 1994;235: 120-140.

61. Collins JG, Kirtland BC, Arnold RR, et al. Experimental periodontitis retards hamster fetal growth. J Dent Res 1995;74: 1171 (Abstract). 
62. Offenbacher S, Jared HL, O'Reilly PG, et al. Potential pathogenic mechanisms of periodontitis associated pregnancy complications. Ann Periodontol 1998;3: 233-250.

63. Offenbacher S, Madianos PN, Suttle M, et al. Elevated human IgM suggests in utero exposure to periodontal pathogens. J Dent Res 1999;78: 2191 (Abstract).

64. Ebersole JL, Machen RL, Steffen MJ, et al. Systemic acute-phase reactants, C-reactive protein and haptoglobin, in adult periodontitis. Clin Exp Immunol 1997;107: 347-352.

65. Ridker PM, Cushman M, Stampfer MJ, et al. Inflammation, aspirin, and the risk of cardiovascular disease in apparently healthy men. N Eng J Med 1997;336: 973-979.

\section{OTHER INTERNET RESOURCES}

http://www.perio.org/

http://cebm.jr2.ox.ac.uk/docs/levels.html

\section{About the Author}

\section{David W. Paquette, DMD, MPH, DMSc}
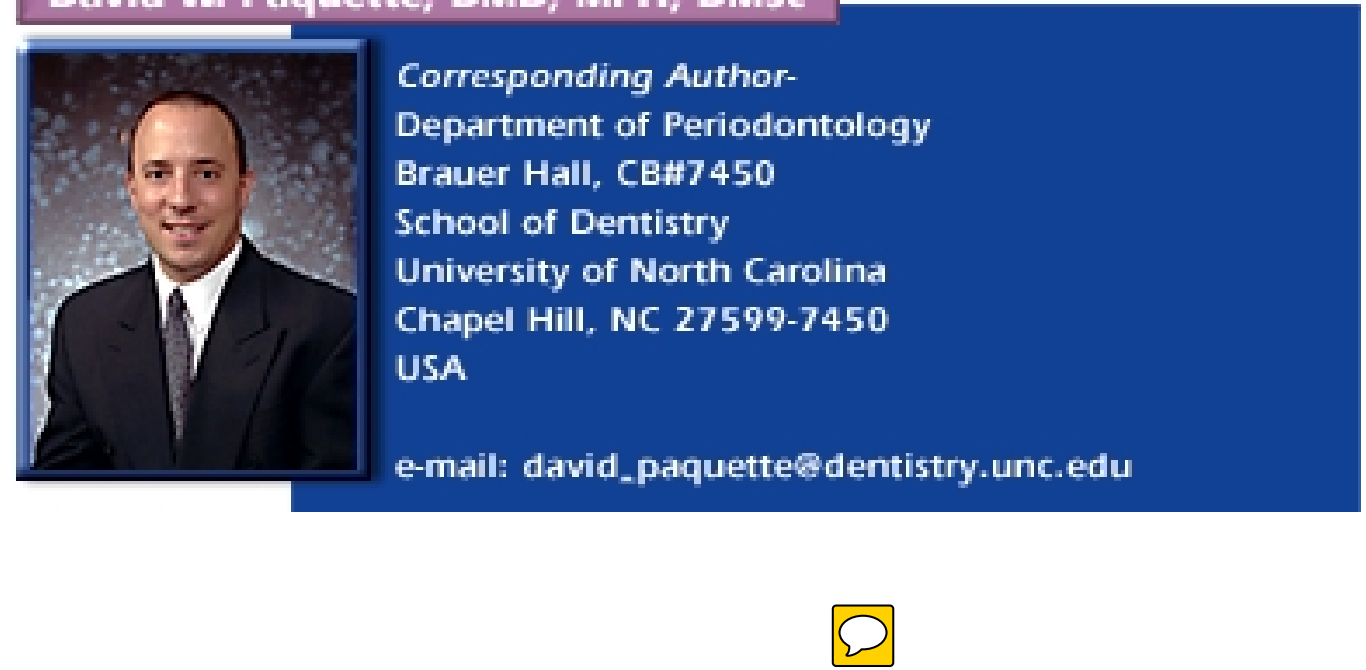